Research Article

\title{
Quercitrin, the Main Compound in Wikstroemia indica, Mitigates Skin Lesions in a Mouse Model of 2,4-Dinitrochlorobenzene- Induced Contact Hypersensitivity
}

\author{
Jonghwan Jegal, ${ }^{1}$ No-June Park, ${ }^{2}$ So-Yeon Lee, ${ }^{1}$ Beom-Geun Jo, ${ }^{1}$ Sim-Kyu Bong, ${ }^{2}$ \\ Su-Nam Kim $(\mathbb{D})^{2}$ and Min Hye Yang ${ }^{1}{ }^{1}$ \\ ${ }^{1}$ College of Pharmacy, Pusan National University, Busan 46241, Republic of Korea \\ ${ }^{2}$ Natural Products Research Institute, Korea Institute of Science and Technology, Gangneung 25451, Republic of Korea \\ Correspondence should be addressed to Su-Nam Kim; snkim@kist.re.kr and Min Hye Yang; mhyang@pusan.ac.kr
}

Received 18 April 2020; Accepted 29 May 2020; Published 9 July 2020

Guest Editor: Xiangguo Shi

Copyright (c) 2020 Jonghwan Jegal et al. This is an open access article distributed under the Creative Commons Attribution License, which permits unrestricted use, distribution, and reproduction in any medium, provided the original work is properly cited.

\begin{abstract}
Hapten-induced contact hypersensitivity (CHS) is widely utilized to induce immune activation in animal models of allergic contact dermatitis. Our previous findings suggested that the $95 \%$ EtOH extract of Wikstroemia indica (L.) C. A. Mey. has antiallergic and anti-inflammatory effects in DNCB-treated CHS SKH-1 hairless mice. The aim of this study was to evaluate the protective effects of compounds isolated from the EtOAc fraction of $W$. indica in RBL-2H3 cells and 2,4-dinitrochlorobenzene(DNCB-) induced CHS mice. Of eight compounds in $W$. indica, that is, umbelliferone, daphnoretin, wikstrocoumarin, (+)-syringaresinol, tricin, (+)-lariciresinol, erythro-guaiacylglycerol- $\beta$-coniferyl ether, and quercitrin, quercitrin exhibited the most antiallergic activity against antigen-induced $\beta$-hexosaminidase release and IL-4 mRNA expression, which are markers of degranulation in RBL-2H3 cells. After a 7-sensitizing period, 14 days of DNCB treatment with or without topical pimecrolimus $(1 \%)$ or quercitrin $(0.5 \%)$ treatment, quercitrin was found to suppress DNCB-induced increases in serum IL-4 and IgE concentrations and transepidermal water loss. These results indicate that quercitrin has therapeutic potential for treatment of allergies and allergy-related contact dermatitis.
\end{abstract}

\section{Introduction}

Contact hypersensitivity (CHS) is one of the most common skin inflammatory diseases and affects $15-20 \%$ of individuals worldwide [1]. Contact hypersensitivity is a type IV delayed hypersensitivity mediated by T cells and manifests as an eczematous skin condition that occurs when a substance (e.g., urushiol from poison ivy, a fragrance, or nickel) that acts as an allergen or hapten comes into contact with skin [2-4]. Contact hypersensitivity occurs in two phases, namely, a sensitization phase and an elicitation phase [5]. The sensitization phase occurs when a hapten applied to skin is first introduced to the immune system [6, 7]. Langerhans cells recognize haptens and then mature, migrate to lymph nodes, and present processed haptens to naive $\mathrm{T}$ cells. These sensitized naive $\mathrm{T}$ cells then migrate to epidermis and differentiate into effector T cells $[4,8]$. These processes involve cytokines such as IL- $1 \beta$, IL-12, and TNF- $\alpha[4,5]$. Subsequently, when sensitized skin is reexposed to a hapten, the elicitation phase of CHS begins. This reexposure of hapten to "sensitized" $\mathrm{T}$ cells results in the explosive differentiation and proliferation of $\mathrm{T}$ cells [9], and cytokines secreted by these $\mathrm{T}$ cells stimulate cells in skin, which leads to the recruitment of T cells and the enhancement of inflammation at hapten-challenged sites $[9,10]$. The cytokines of INF- $\gamma$, IL-4, and IL-17 play major roles during the elicitation phase $[5,6]$.

Flavonoids are a group of aromatic ring compounds with a C6-C3-C6 composition and occur widely in plants (about 400 plant species have been identified) [11]. Flavonoids act as pigments that color fruits and flowers and are also 
involved in plant growth and defense [12]. Fruits, vegetables, and medicinal plants contain large quantities of flavonoids, and much research has shown they have many beneficial effects $[13,14]$. In particular, several studies have demonstrated the antiallergic, anti-inflammatory, and antioxidant effects of flavonoids $[15,16]$. Naturally occurring flavonoids reduce the productions of inflammatory cytokines secreted by mast cells, basophils, and Th cells in immunoglobulin $E$ (IgE-) mediated allergies [17-21]. Wikstroemia indica (L.) C. A. Mey. (Thymelaeaceae) is a plant native to Southeast Asia and China and is used in Chinese traditional medicine to treat coughs, syphilis, and arthritis [22]. W. indica contains diverse flavonoids, such as quercetin and epicatechin, with anti-inflammatory and antioxidant activities [23-25]. In a previous report, our findings supported the use of $W$. indica to treat types of allergic contact dermatitis like atopic dermatitis [26]. However, relatively few studies have indicated that flavonoids isolated from this plant are effective on skin inflammatory diseases. The aim of the present study was to isolate bioactive flavonoids from $W$. indica and to investigate their preventive and therapeutic potentials on CHS.

\section{Materials and Methods}

2.1. General Methods. NMR spectra were recorded using a Varian Unity INOVA 400 spectrometer $(400 \mathrm{MHz}$ for $1 \mathrm{H}$ and $101 \mathrm{MHz}$ for 13C-NMR) (Agilent Technologies, Santa Clara, CA, USA) and Bruker Avance NEO 500 spectrometer system (COSY, HMQC, HMBC, and NOESY) (Bruker, Billerica, MA, USA). High-performance liquid chromatography (HPLC) was performed using a Shimadzu system (Shimadzu Corporation, Kyoto, Japan), which consisted of a LC-20ATpump, SPD-20A UV detector, and CBM-20A system controller. High-resolution electrospray ionization mass spectra (HRESIMS) were obtained using an Agilent 6530 Accurate-Mass Q-TOF LC/MS spectrometer system (Agilent Technologies, Santa Clara, CA, USA). Column chromatography (CC) was performed on silica gel (230-400 mesh, Merck, Germany) and Sephadex LH-20 (25-100 mM mesh, Pharmacia, Sweden) and thin-layer chromatography (TLC) on precoated silica gel 60 F254 (1.05554.0001, Merck, Germany) plates. Spots were visualized by spraying $\mathrm{p}$-anisaldehyde solution.

2.2. Plant Material and Extraction. The aerial portions of Wikstroemia indica (L.) C. A. Mey (Thymelaeaceae) were collected from a village called Jobra in Chittagong, Bangladesh. A voucher specimen (PNU-0026) was deposited at the Medicinal Herb Garden of Pusan National University (Busan, Republic of Korea). Plant materials were authenticated by Dr. Sang Woo Lee (Korea Research Institute of Bioscience and Biotechnology). Dried W. indica $(4 \mathrm{~kg})$ was sonicated in $95 \%$ EtOH $(12 \mathrm{~L} \times 3)$ for $90 \mathrm{~min}$ and allowed to stand overnight. The extract solvent was then filtered through Advantec No. 2 filter paper (Advantec, Toyo Roshi Kaish, Ltd., Tokyo). The $95 \% \mathrm{EtOH}$ extract of $W$. indica $(247.6 \mathrm{~g})$ was then obtained by evaporating the $\mathrm{EtOH}$ extract. The $95 \% \mathrm{EtOH}$ extract of $W$. indica (WIE) was suspended in water $(2.2 \mathrm{~L})$ and fractioned versus $n$-Hex (15.7 g), EtOAc (20.1 g), and $n$-BuOH (16.4 g).
2.3. Isolation of Compounds from Wikstroemia indica. WIE $(247.6 \mathrm{~g})$ was suspended in distilled water $(2.2 \mathrm{~L})$ and sequentially partitioned versus $n$-Hex (4.6L), EtOAc (7.2 L), and $n-\mathrm{BuOH}(6.4 \mathrm{~L})$. In addition, the EtOAc fraction of $W$. indica 95\% EtOH extract (WIE-EtOAc, $20.1 \mathrm{~g}$ ) was chromatographed on a silica gel column using an $n$-hexane-EtOAc $(10: 1 \longrightarrow 100 \% \mathrm{MeOH}$, gradient system $)$ to yield twelve fractions (WIE1-WIE12). Compound 1 (umbelliferone, $117.8 \mathrm{mg}$ ) was obtained as pure powder by filtering fraction WIE4. Compound 2 (daphnoretin, $16.5 \mathrm{mg}$ ) was obtained by recrystallizing fraction WIE7 $(1.06 \mathrm{~g})$ from $\mathrm{MeOH}$ and refractioning to produce seven subfractions (WIE7-1-WIE77) by silica gel CC (column chromatography) using a $\mathrm{CH}_{2} \mathrm{CI}_{2}-$ $\mathrm{MeOH}(7: 1 \longrightarrow 100 \% \mathrm{MeOH})$ gradient system. Subfraction WIE7-1 (128.6 mg) was fractionated into six subfractions (WIE7-1-1-WIE7-1-6) by Sephadex LH-20 CC using 100\% $\mathrm{MeOH}$ as eluant. Compound 3 (wikstrocoumarin, $2.4 \mathrm{mg}$ ) was obtained by filtering fraction WIE7-1-3. Subfraction WIE7-1-2 $(17.4 \mathrm{mg})$ was fractionated into five subfractions (WIE7-1-21-WIE7-1-2-5) by PTLC (preparative thin-layer chromatography) using $\mathrm{CH}_{2} \mathrm{CI}_{2}-\mathrm{MeOH}(15: 1)$ as eluant. Subfraction WIE7-1-2-5 (6.2 mg, Rf 0.88) was subjected to RP HPLC (Watchers 120 ODS-BP, S- $10 \mu \mathrm{m}, 250 \times 10 \mathrm{~mm}$; detection, UV at $254 \mathrm{~nm}$; flow rate, $2 \mathrm{~mL} / \mathrm{min}$ ) and eluted with an isocratic ACN- $\mathrm{H}_{2} \mathrm{O}$ system $(3: 7,40 \mathrm{~min})$ to yield compound 4 ((+)-syringaresinol, $\left.1.4 \mathrm{mg}, t_{\mathrm{R}} 27 \mathrm{~min}\right)$. Subfraction WIE7-2 (158 mg) was fractionated into seven subfractions (WIE7-21-WIE7-2-7) by Sephadex LH-20 CC using $100 \% \mathrm{MeOH}$ as eluant. Compound 5 (tricin, $1.6 \mathrm{mg}$ ) was obtained as pure powder by filtering fraction WIE7-2-7. Subfraction WIE7-2-3 (40.2 mg) was subjected to PTLC using $\mathrm{CH}_{2} \mathrm{Cl}_{2}-\mathrm{MeOH}(10: 1)$ as eluent to yield compound $6((+)$-lariciresinol, $8 \mathrm{mg}, \mathrm{R} f 0.64)$. Fraction WIE8 (441.1 mg) was subjected to silica gel CC using a $\mathrm{CH} 2 \mathrm{Cl} 2-\mathrm{MeOH}(30: 1 \longrightarrow 100 \% \mathrm{MeOH}$, gradient system) to yield five fractions (WIE8-1-WIE8-5). Subfraction WIE8-3 $(61.7 \mathrm{mg})$ was fractionated into five subfractions (WIE8-31-WIE8-3-5) by Sephadex LH-20 CC using $100 \% \mathrm{MeOH}$ as eluent, and subfraction WIE8-3-2 (10.3 mg) was subjected to RP HPLC (Watchers 120 ODS-BP, S- $10 \mu \mathrm{m}, 250 \times 10 \mathrm{~mm}$; detection, $U V$ at $254 \mathrm{~nm}$; flow rate, $2 \mathrm{~mL} / \mathrm{min}$ ) and eluted with a $\mathrm{MeOH}-\mathrm{H}_{2} \mathrm{O}$ isocratic system $(4: 6,30 \mathrm{~min})$ to yield compound 7 (erythro-guaiacylglycerol- $\beta$-coniferyl ether, $1.9 \mathrm{mg}, t_{\mathrm{R}}$ $19 \mathrm{~min})$. Fraction WIE9 (10.5 g) was chromatographed on a silica gel column using $\mathrm{CH}_{2} \mathrm{Cl}_{2}-\mathrm{MeOH} \quad(10: 1 \longrightarrow 100 \%$ $\mathrm{MeOH}$, gradient system) as eluent to yield eight fractions (WIE9-1-WIE9-8). Subfraction WIE9-7 (275.2 mg) was fractionated into four subfractions (WIE9-7-1-WIE9-7-4) by Sephadex LH-20 C.C using $100 \% \mathrm{MeOH}$ as eluent. Compound 8 (quercitrin, $101.4 \mathrm{mg}$, purity $\geq 98 \%$, HPLC) was obtained as pure powder by filtering fraction WIE9-7-3.

2.4. Cell Culture. The RBL-2H3 mast cell line was purchased from the American Type Culture Collection (ATCC, \#CRL2256, Manassas, VA, USA) and cultured in minimum essential medium (MEM) supplemented with $2 \mathrm{mM} \cdot \mathrm{L}$-glutamine, $100 \mu / \mathrm{mL}$ penicillin, $100 \mu \mathrm{g} / \mathrm{mL}$ streptomycin, and $10 \% \mathrm{v} / \mathrm{v}$ heat-inactivated fetal bovine serum (FBS). Cells were maintained at $37^{\circ} \mathrm{C}$ in a humidified atmosphere containing $5 \% \mathrm{CO}_{2}$. 
2.5. Analysis of IL-4 mRNA Expression by Real-Time PCR. To assess the effect of compounds isolated from $W$. indica on the mRNA expression of interleukin 4 (IL-4) in RBL-2H3 cells, cells were sensitized to DMSO or compounds $(10 \mu \mathrm{M}$ and $30 \mu \mathrm{M}$ ) for 30 minutes and later stimulated with phorbol 12-myristate 13-acetate (PMA, $50 \mathrm{ng} / \mathrm{mL}$ ) and ionomycin $(1 \mu \mathrm{M})$ for 16 hours. Total RNA was extracted using RNAiso Reagent (TaKaRa, Shiga, Japan), and SYBR Green based quantitative real-time PCR (qPCR) was performed according to the manufacturer's instructions. Data were analyzed using 7500 System SDS software version v1.3.1 (Applied Biosystems). The primer sequences used for IL-4 were $5^{\prime}$-ACC TTG CTG TCA CCC TGT TC-3' (forward) and $5^{\prime}$-TTG TGA GCG TGG ACTCAT TC- $3^{\prime}$ (reverse), and the primer sequences of the housekeeping gene ( $\beta$-actin) were $5^{\prime}$-TCA TCA CCA TCG GCA ACG-3' (forward) and 5'-TTC CT GAT GTC CAC GTC GC-3' (reverse).

2.6. Release Activity of $\beta$-Hexosaminidase. RBL- $2 \mathrm{H} 3$ cells were suspended in MEM media at $1 \times 10^{5}$ cells per well in a 24-well plate and sensitized with anti-DNP IgE for 24 hours. They were then washed in Siraganian buffer ( $\mathrm{pH} 7.5 ; 100 \mathrm{ng} /$ $\mathrm{ml}$ DNP-IgE, $119 \mathrm{mM} \mathrm{NaCl}, 5 \mathrm{mM} \mathrm{KCl}, 0.4 \mathrm{mM} \mathrm{MgCl}_{2}$, $25 \mathrm{mM}$ PIPES, and $40 \mathrm{mM} \mathrm{NaOH}$ ) twice and incubated for 10 minutes in the same buffer. Cells were then treated with DMSO or compounds $(10 \mu \mathrm{M}$ and $30 \mu \mathrm{M})$ for 1 hour, with $1 \mu \mathrm{g} / \mathrm{mL}$ DNP-BSA antigen for 30 minutes to induce cell degranulation, and then supernatants obtained by microcentrifugation were transferred to 96-well plates and incubated with substrate solution $(1 \mathrm{mM}$ poly-N-acetyl glucosamine in $0.1 \mathrm{M}$ sodium citrate buffer) for 3 hours at $37^{\circ} \mathrm{C}$. Finally, stop solution was added and well absorbances were measured using a microplate reader at $405 \mathrm{~nm}$.

2.7. Animal Experiments. SKH-1 hairless mice (females, 6 weeks old) were procured from Orient Bio Inc. (Seongnam, Republic of Korea). All mice were housed under $12 \mathrm{~h}$ lightdark cycle and controlled conditions ( $\mathrm{RH} 55 \pm 5 \%$ and $25 \pm 5^{\circ} \mathrm{C}$ ) for 1 week before experimentation and fed a standard laboratory diet and water ad libitum. Mice care and experimental protocols were approved by the Institutional Animal Care and Use Committee of KIST (Certification No. KIST-2016-011) beforehand and were in accordance with the Guide for the Care and Use of Laboratory Animals published by the US National Institute of Health (NIH Publication No. 85-23, 2011 revision). For CHS induction, SKH-1 hairless mice were acclimated for 1 week and then divided into 4 groups of 7 animals; a normal control group (animals were treated with distilled water), a negative control group $(0.1 \%$ DNCB plus vehicle), a positive control group $(0.1 \% \mathrm{DNCB}$ and $1 \%$ pimecrolimus), and an experimental group $(0.1 \%$ DNCB sensitized plus treatment with $1 \%$ quercitrin). On day 1 , mice were sensitized by applying $1 \%$ DNCB $(100 \mu \mathrm{L})$ dissolved in propylene glycol and ethanol $(7: 3)$ topically to dorsal skins for 7 days to induced CHS (day 1 to day 7 ). Mice were stimulated with $0.1 \% \operatorname{DNCB}(100 \mu \mathrm{L})$ for 2 weeks (day 8 to 21) at 2-day intervals, and $\mathrm{DNCB}+$ quercitrin group and

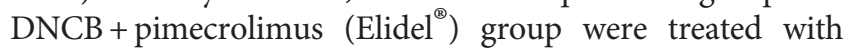

$0.5 \%$ quercitrin $(100 \mu \mathrm{L})$ and $1 \%$ pimecrolimus cream twice daily (day 8 to 21). On day 22, animals were sacrificed, and dorsal skin tissue was removed for histological examination and blood was collected from abdominal aortas for serum IgE and IL-4 testing.

2.8. Measurement of Skin Conditions. All experiments used to assess skin conditions were performed at $25 \pm 5^{\circ} \mathrm{C}$ and $50 \pm 5 \%$ RH. Transepidermal water loss (TEWL) was measured using a Tewameter TM210 (Courage and Khazaka, Cologne, Germany) with an open chamber system. Skin barrier damage was expressed in $\mathrm{g} / \mathrm{m}^{2} / \mathrm{h}$. A SKIN-O-MAT device (Cosmomed, Ruhr, Germany) was used to measure hydration levels of mouse skins.

2.9. Total Serum IgE and IL-4 Levels. Blood was collected from abdominal aortas on day 22, centrifuged at 10,000 rpm for 15 minutes at $4^{\circ} \mathrm{C}$, and stored at $-70^{\circ} \mathrm{C}$ until needed for IgE and IL-4 measurements. Total serum IgE and IL-4 levels were quantified using an enzyme-linked immunosorbent assay kit (eBioscience, San Diego).

2.10. Histological Analysis. Dorsal skin samples were fixed in $10 \%$ neutral buffered formalin (NBF) and embedded in paraffin. Sections of dorsal skin (4-6 $\mu \mathrm{m}$ thickness) were stained with hematoxylin and eosin (H\&E) to evaluate eosinophil infiltration or with toluidine blue to count mast cell numbers. Dorsal skin tissues were visualized under a light microscope (Olympus CX31/BX51, Olympus Optical Co., Tokyo) and photographed (TE-2000U, Nikon Instruments Inc., Melville, USA).

2.11. Statistical Analysis. Statistical analysis was performed using one-way ANOVA followed by Tukey's HSD multiple comparison test. Results are presented as mean \pm standard deviations, and statistical significance was accepted for $p$ values $<0.05$.

\section{Results}

3.1. Isolation of Compounds from WIE-EtOAc and Their Effects on $\beta$-Hexosaminidase Release from and IL-4 Expression in $\mathrm{RBL}-2 \mathrm{H} 3$ Cells. The in vitro antiallergic and anti-inflammatory activities of WIE and its fractions ( $n$-hexane, EtOAc, $n$ - $\mathrm{BuOH}$, and water) were evaluated and the EtOAc fraction was the most active in RBL-2H3 cells (data not shown). The WIE-EtOAc was subjected to silica gel column chromatography, Sephadex LH-20 column chromatography, and RP HPLC to yield eight known compounds, namely, umbelliferone (1), daphnoretin (2), wikstrocoumarin (3), (+)-syringaresinol (4), tricin (5), (+)-lariciresinol (6), erythroguaiacylglycerol- $\beta$-coniferyl ether (7), and quercitrin (8) (Figure 1). Compounds were identified by comparing ${ }^{1} \mathrm{H}$ NMR, ${ }^{13} \mathrm{C}-\mathrm{NMR}$, and MS data with literature values.

To investigate the inhibitory effect of WIE-EtOAc on cell degranulation, RBL-2H3 cells were sensitized with $\operatorname{IgE}$ and activated with DNP-BSA. The results obtained showed that 
<smiles>O=c1ccc2ccc(O)cc2o1</smiles><smiles>COc1cc2cc(Oc3ccc4ccc(=O)oc4c3)c(=O)oc2cc1O</smiles>

2<smiles>COC(=O)CCc1ccc(Oc2cc3cc(OC)c(O)cc3oc2=O)cc1O</smiles><smiles>COc1cc([C@@H]2OC[C@@H]3[C@H]2CO[C@H]3c2cc(OC)c(O)c(OC)c2)cc(OC)c1O</smiles>

4<smiles>COc1cc(-c2cc(=O)c3c(O)cc(O)cc3o2)cc(OC)c1O</smiles><smiles>COc1cc(C[C@@H]2CO[C@@H](c3ccc(O)c(OC)c3)[C@H]2CO)ccc1O</smiles><smiles>COc1cc([C@@H](O)[C@@H](CO)Oc2ccc(/C=C/CO)cc2OC)ccc1O</smiles>

7<smiles>C[C@@H]1O[C@H](Oc2c(-c3ccc(O)c(O)c3)oc3cc(O)cc(O)c3c2=O)[C@H](O)[C@H](O)[C@@H]1O</smiles>

8

Figure 1: Chemical structures of compounds isolated from EtOAc fraction of the 95\% EtOH extract of W. indica (WIE-EtOAc): 1, umbelliferone; 2, daphnoretin; 3, wikstrocoumarin; 4, (+)-syringaresinol; 5, tricin; 6, (+)-lariciresinol; 7, erythro-guaiacylglycerol$\beta$-coniferyl ether; 8 , quercitrin.

degranulation increased 3 times more in DNP/IgE-induced cells than in controls. However, treatment with compounds $1,6,7$, and 8 effectively suppressed antigen-mediated $\beta$-hexosaminidase release from cells (Figure 2). The suppressive effects of compounds in WIE-EtOAc on IL-4 mRNA expression were investigated using phorbol 12myristate 13-acetate (PMA) + ionomycin- (PI-) stimulated RBL-2H3 cells. It was observed that IL-4 mRNA expression in PI treated cells was greater than in controls, but that compounds $1,2,4,5,6,7$, and 8 reduced IL-4 mRNA levels (Figure 3). In particular, quercitrin (8) was the compound that suppressed DNP/IgE-induced $\beta$-hexosaminidase release (74.1\% inhibition) and IL-4 mRNA expression by PI (86.7\% inhibition) at $30 \mu \mathrm{M}$.

\subsection{Effects of Quercitrin from WIE-EtOAc on DNCB-Induced} CHS in SKH-1 Hairless Mice. To investigate the effects of quercitrin from WIE-EtOAc on DNCB-induced skin symptoms, dermatitis levels were evaluated using skin images. The procedure used to establish the DNCB-induced CHS model is shown in Figure 4(a). DNCB treatment for 3 weeks resulted in severe CHS-like skin symptoms, that is, dried skin, cornification, exudation, and erythema, and these symptoms were markedly improved by $0.5 \%$ quercitrin treatment for 2 weeks and this improvement was similar to that observed in the 1\% Elidel-treated group (the positive control group) (Figure 4(b)).

3.3. Effects of Quercitrin from WIE-EtOAc on Skin Histopathological Changes in DNCB-Induced CHS Mice. To evaluate the histological changes induced by quercitrin in the dorsal skins of DNCB-induced CHS mice, we used $\mathrm{H} \& \mathrm{E}$ and toluidine blue staining. H\&E results showed that epidermis thickness was significantly greater in the DNCB group than in the CON group. However, epidermis thickness in the $0.5 \%$ quercitrin group was $77.8 \%$ lower than that in the DNCB group (Figures 5(a) and 5(c)). Toluidine blue staining showed mast cell numbers were greater in the DNCB group than in the CON group and that mast cell numbers were $66.7 \%$ lower in the quercitrin group (Figures $5(\mathrm{~b})$ and $5(\mathrm{~d})$ ), which was a greater reduction in numbers than that observed in the Elidel group.

3.4. Effects of Quercitrin from WIE-EtOAc on Serum IgE and IL-4 Levels in DNCB-Induced CHS Mice. To measure levels of IgE and IL-4, blood samples were collected from abdominal aortas of DNCB-induced SKH-1 hairless mice and serum IgE and IL-4 concentrations were measured by ELISA. IgE was 5.2-fold higher and IL-4 was 3.8-fold higher in the 


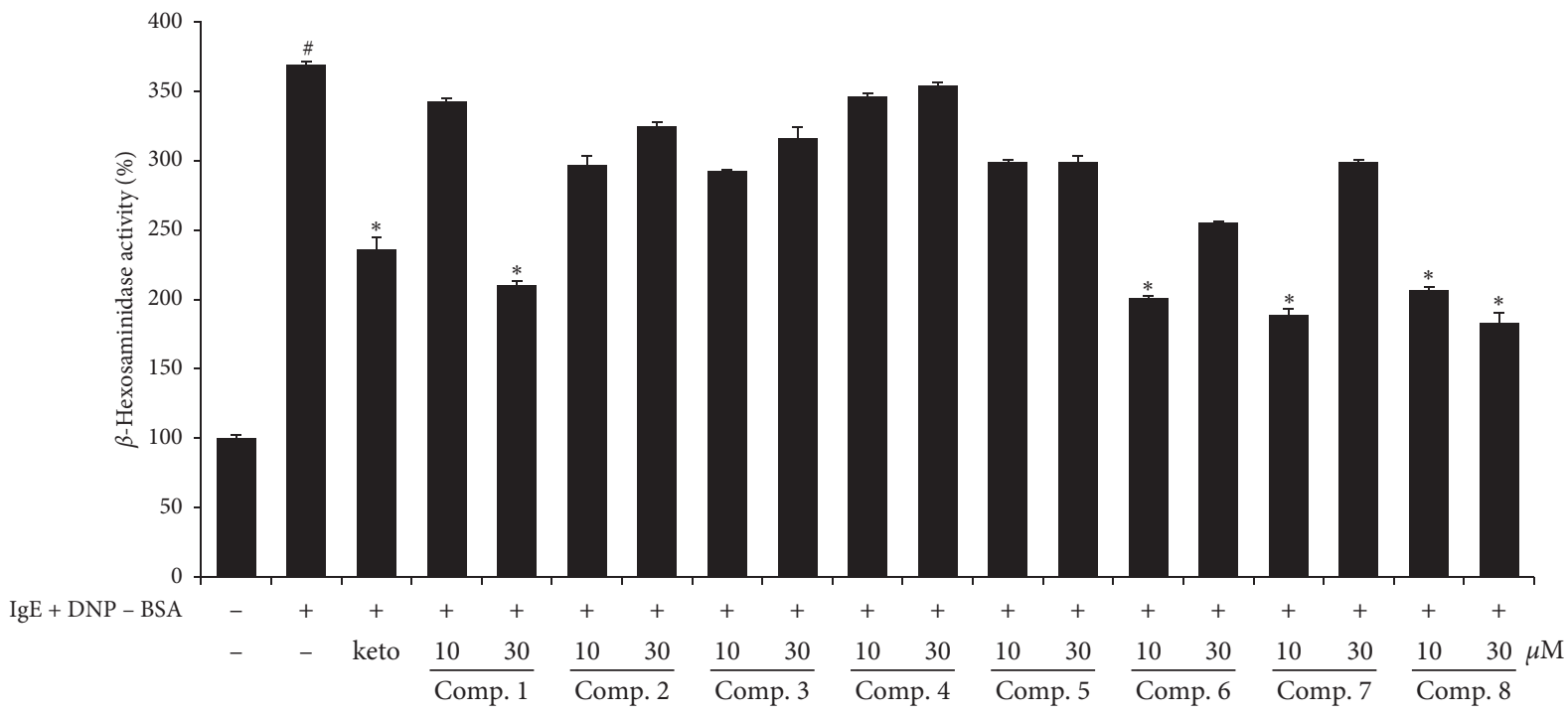

Figure 2: Effects of compounds isolated from WIE-EtOAc on $\beta$-hexosaminidase release from IgE-activated RBL-2H3 cells. Results are presented as mean \pm SDs of two independent experiments performed in triplicate. ${ }^{\#} p<0.05$ versus vehicle controls; Ket: $35 \mu \mathrm{M}$ ketotifen.

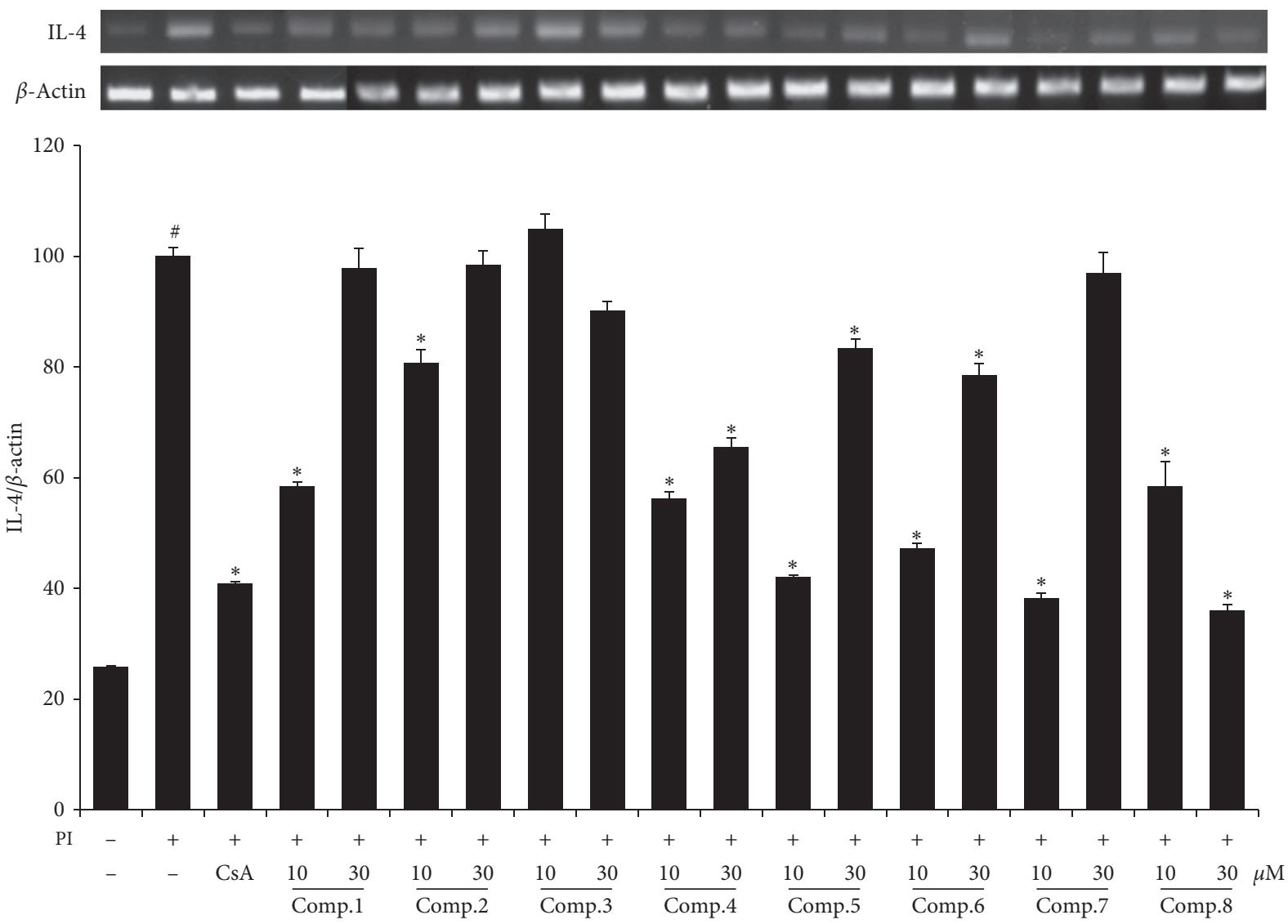

FIgURE 3: Effects of compounds isolated from WIE-EtOAc on IL-4 mRNA expression in PI-activated RBL-2H3 cells. Results are presented as mean \pm SDs of two independent experiments performed in triplicate. ${ }^{\#} p<0.05$ versus vehicle controls; ${ }^{*} p<0.05$ versus PI. CsA: $1 \mu \mathrm{M}$ cyclosporine A.

DNCB group than in the CON group. However, $0.5 \%$ quercitrin treatment significantly decreased the serum $\operatorname{IgE}$ and IL-4 level increases induced by DNCB to $52.4 \%$ and $62.5 \%$, respectively (Figure 6).
3.5. Effects of Quercitrin from WIE-EtOAc on Skin Barrier Function in DNCB-Induced CHS Mice. Changes in skin barrier function after treatment with $0.5 \%$ quercitrin for 2 weeks were evaluated by measuring TEWL and skin hydration. 


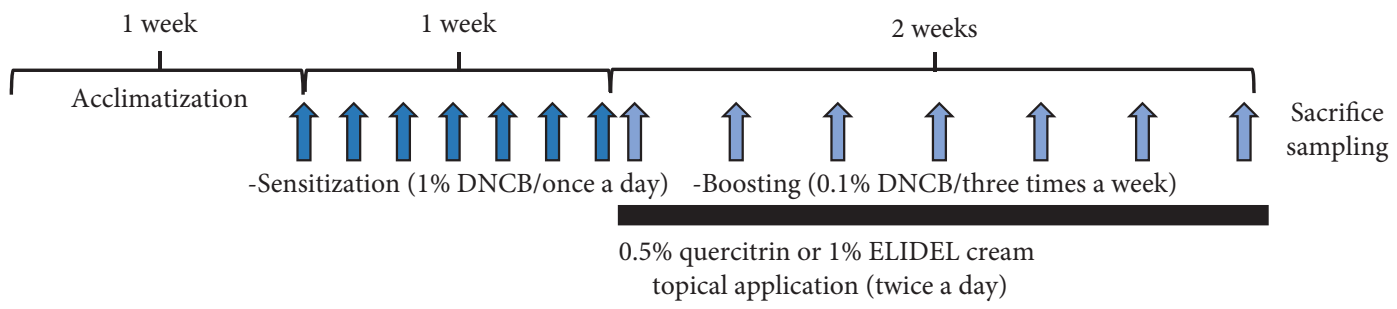

(a)

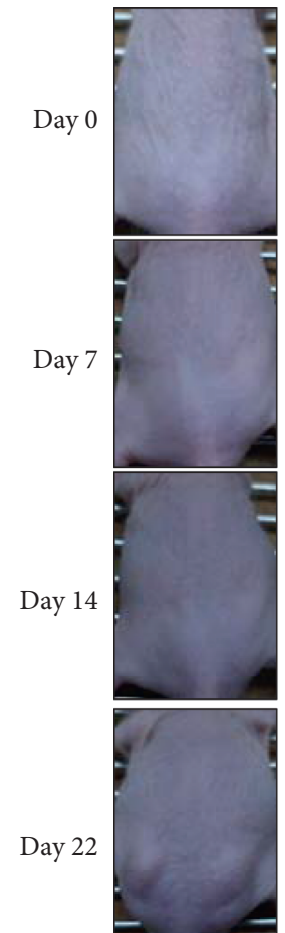

$\mathrm{CON}$

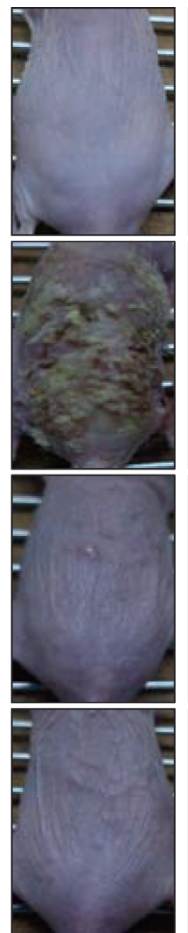

DNCB

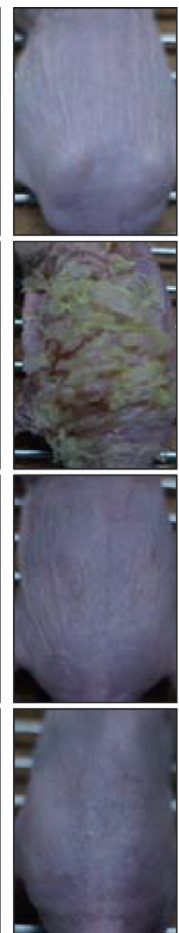

DNCB

+ quercitrin

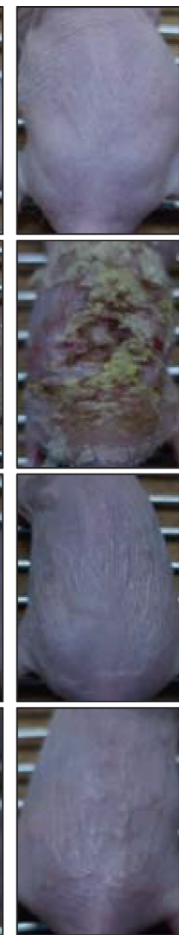

DNCB

+ ELIDEL

(b)

FIGURE 4: Effects of quercitrin on the development of DNCB-induced CHS in SKH-1 hairless mice. (a) Schematic representation of the experiment. (b) Clinical features of DNCB-induced skin symptoms. Values represent the mean SD $(n=7)$. CON: vehicle control group; $\mathrm{DNCB}+$ vehicle: DNCB-treated control group; $\mathrm{DNCB}+$ quercitrin: $\mathrm{DNCB}$ and $0.5 \%$ quercitrin-treated group; DNCB + Elidel: DNCB and $1 \%$ Elidel-treated group.

The results showed that TEWL was 2.7 -fold higher and skin hydration was 0.3 -fold lower in the DNCB group than in the CON group. However, $0.5 \%$ quercitrin treatment significantly reduced this TEWL DNCB-induced increase to $50 \%$ and improved skin hydration to $32.4 \%$ (Figure 7).

\section{Discussion}

The skin is made up of several tightly connected layers that are in combination function as a primary barrier, which protects the body from harm, prevents the entry of exogenous substances, and reduces water loss [27]. If the skin barrier is damaged, external antigens are likely to penetrate, and this causes T-helper 2 (Th2) cell-mediated immune response and subsequent inflammation [28]. Furthermore, excessive, prolonged inflammatory reactions cause tissue damage, which in turn detrimentally affects the skin barrier and establishes a vicious cycle [29]. Skin barrier dysfunction and immune system dysregulation are the main causes of skin inflammatory diseases [30]. Because skin barrier dysfunction plays an important role in the development of allergic contact dermatitis, strengthening this barrier is considered a primary strategy for preventing and treating contact dermatitis [31,32]. Several methods can be used to assess skin barrier dysfunction, and TEWL provides a simple and noninvasive means of doing so [33]. The TEWL values of patients with allergic contact dermatitis are higher than those of healthy individuals [34].

Our previous study of WIE revealed that its topical application on the dorsal skins of mice decreased the severity of DNCB-induced allergic contact dermatitis by reducing edema, erythema, and inflammation [26]. The therapeutic 


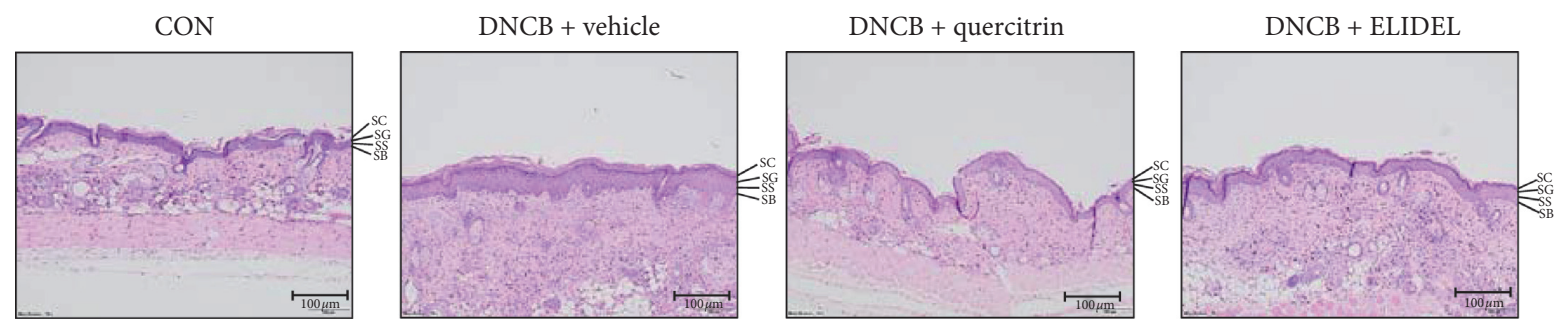

SC : Stratum corneum, SG : Stratum granulosum, SS : Stratum spinosum, SB : Stratum basale

(a)
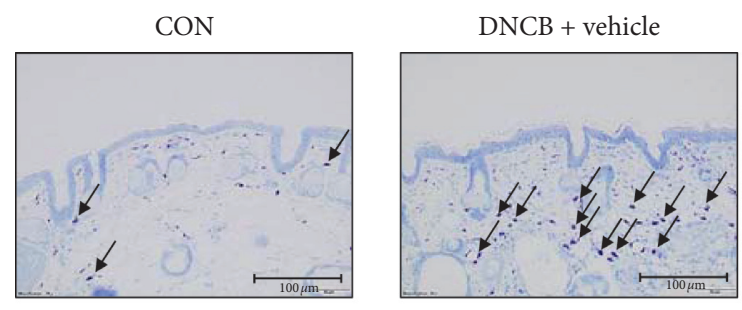

$\mathrm{DNCB}+$ quercitrin

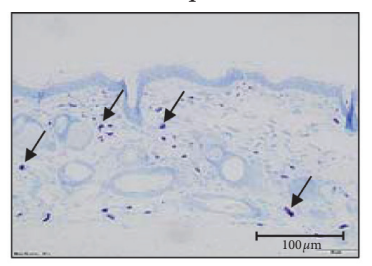

b)

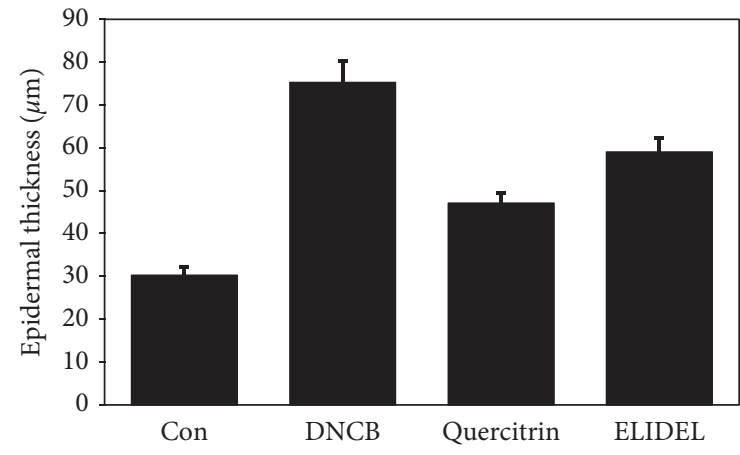

(c)

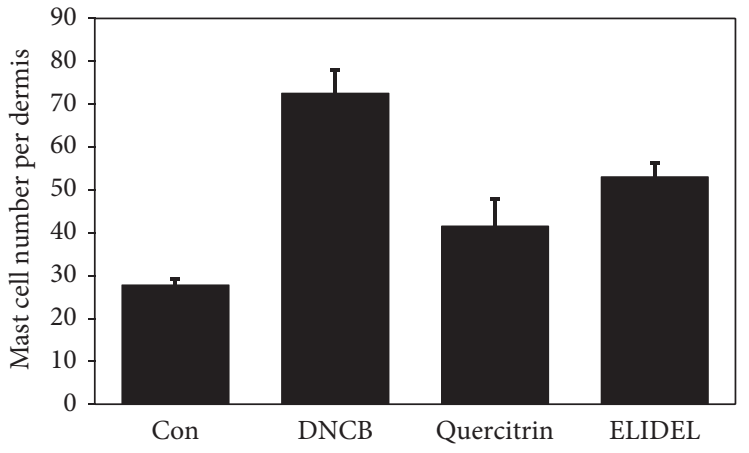

(d)

FIGURE 5: Effects of quercitrin on skin histopathological changes, epidermal thickness, and mast cell numbers in DNCB-induced CHS mice. (a) H\&E staining. (b) Toluidine blue staining. (c) Epidermal thicknesses. (d) Mast cell numbers. Values represent the mean SD ( $n=7)$. CON: vehicle control group; $\mathrm{DNCB}+$ vehicle: $\mathrm{DNCB}$-treated control group; $\mathrm{DNCB}+$ quercitrin: $\mathrm{DNCB}$ and $0.5 \%$ quercitrin-treated group; DNCB + Elidel: DNCB and $1 \%$ Elidel-treated group. ${ }^{\#} p<0.05$ versus the CON group; ${ }^{*} p<0.05$ versus the DNCB group.

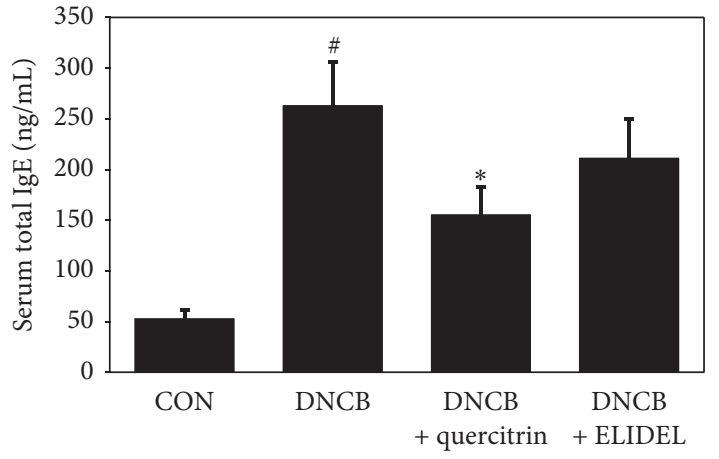

(a)

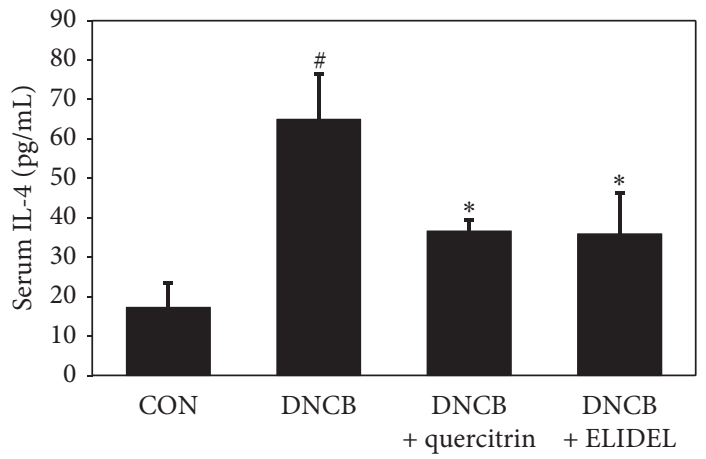

(b)

FIgURE 6: Effects of quercitrin on serum IgE and IL-4 levels in DNCB-induced CHS mice. (a) Serum total IgE levels. (b) Serum IL-4 levels. ${ }^{\#} p<0.05$ versus the CON group; ${ }^{*} p<0.05$ versus the DNCB group. 


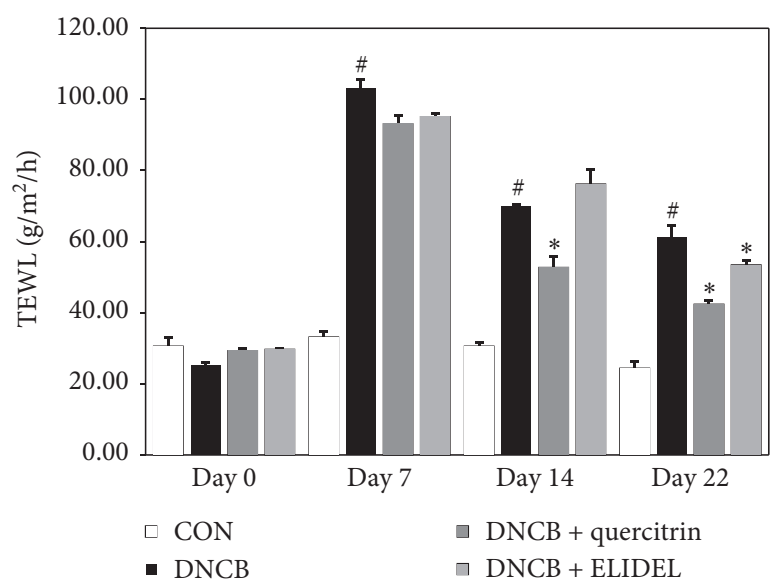

(a)

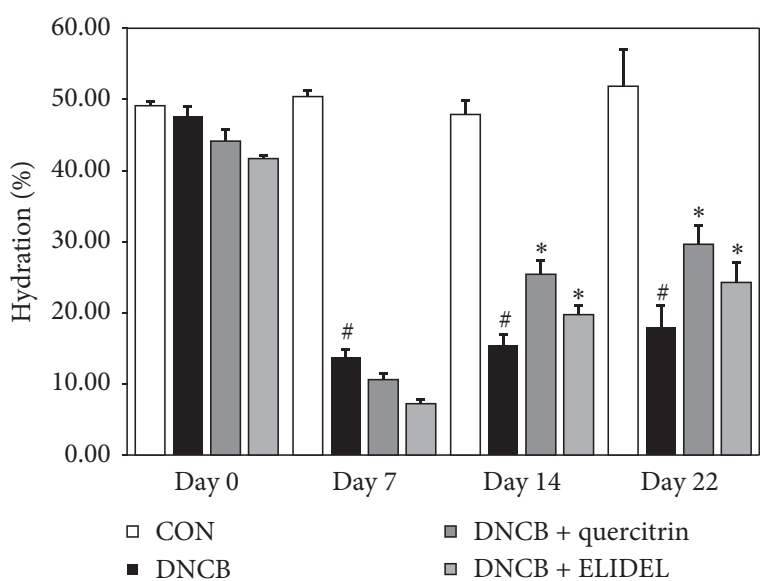

(b)

FIGURE 7: Effects of quercitrin on skin barrier function in DNCB-induced CHS mice. (a) Transepidermal water loss (TEWL). (b) Skin hydration. ${ }^{\#} p<0.05$ versus the CON group; ${ }^{*} p<0.05$ versus the DNCB group.

effects of WIE against hapten-induced CHS are believed to be due to skin barrier recovery and the subsequent inhibition of IL-4. Accordingly, attempts have been made to develop a procedure for separating biologically active components from WIE. In the present study, flavonoids, lignans, and coumarins were isolated from an EtOAc fraction of WIE using various chromatographic methods, and of these isolated compounds, quercitrin (a glycoside of quercetin) exhibited strong in vitro inhibitory activities against DNP/IgE-induced $\beta$-hexosaminidase release and PI-induced IL- $4 \mathrm{mRNA}$ expression. In vivo testing using DNCB-induced CHS mouse model was performed to assess the therapeutic potential of quercitrin for the treatment of contact dermatitis. Murine CHS models are often used to investigate the pathogeneses of human and animal allergic CHS [1]. Typical haptens, such as 2-chloro1,3,5-trinitrobenzene (TNCB), 2,4-dinitro-1-fluorobenzene (DNFB), 2,4-dinitrochlorobenzene (DNCB), and oxazolone, are known to induce rapid CHS in animals [1, 35]. In the present study, the severe CHS reaction induced by DNCB was clearly suppressed by treatment with $0.5 \%$ quercitrin for 2 weeks. Furthermore, barrier functional damage caused by $\mathrm{DNCB}$ was largely prevented by quercitrin. According to the previous literature, Th2 cytokine IL-4 enhances expression of kallikrein 7 (KLK7) and downregulates expression of filaggrin, a key epidermal barrier protein in allergic skin disease [36]. The inhibitory effects of quercitrin on IL-4 production may provide an important clue for the mechanism underlying its skin barrier protective effect.

RBL-2H3 cells are an excellent experimental model for studying the effects of drug involved in Th2 immune responses and have characteristics resembling those of mast cells, for example, they secrete cytokines and histamine, which induce $\mathrm{IgE}$ receptor expression and immune responses on cell surfaces $[37,38]$. In the present study, the antiallergic and anti-inflammatory effects of compounds isolated from WIE were determined using procedures previously used in RBL-2H3 cells. Out of the eight compounds isolated, quercitrin most effectively suppressed $\beta$-hexosaminidase release and IL-4 mRNA expression in RBL-2H3 cells. This data suggests that quercitrin partially inhibits the differentiation of Th0 cells into Th1 cells and decreases IL-4 release in DNCB-stimulated mice. Cytokines produced by T cells, such as IL-4, IL-10, and IFN- $\gamma$, play keys roles during the pathogenesis of CHS [4]. In particular, IL-4 is a pleiotropic cytokine of Th2 cells that regulates immunoglobulin isotype switching to IgG4 and $\operatorname{IgE}$ [39]. In a previous study, it was suggested that total loss of endogenously produced IL- 4 in BALB/c mice was closely associated with impairment of DNCB-induced CHS [35]. This result supports the importance of IL-4 as an immune response regulator during the early phase of skin CHS. We observed the productions and expressions of IL- 4 and IgE were significantly increased in DNCB-sensitized mice in-line with CHS induction and that dermal application of quercitrin, a major constituent of $W$. indica, greatly reduced IL-4 expression, which suggested quercitrin suppresses Th2 immunity in mice CHS.

\section{Conclusion}

Our study shows that quercitrin isolated from $W$. indica has a novel protective effect against CHS in the DNCB-induced SKH-1 hairless mouse model. Furthermore, quercitrin significantly attenuated DNP/IgE-induced $\beta$-hexosaminidase release and PI-induced IL-4 mRNA expression in RBL-2H3 cells. The inhibitory effects of quercitrin on IL-4 and IgE in CHS mice suggest that it might be useful for treating allergic skin disorders. Furthermore, the observed improvement of skin barrier function by quercitrin would seem to have considerable pharmacological potential for the treatment of contact dermatitis.

\section{Abbreviations}

CHS: Contact hypersensitivity

DNCB: 2,4-Dinitrochlorobenzene 
IgE: Immunoglobulin $\mathrm{E}$

IL: Interleukin

WIE: Wikstroemia indica aerial parts 95\% EtOH extract

Th2: T-helper cell type-2

TEWL: Transepidermal water loss.

\section{Data Availability}

The datasets used and/or analyzed during the current study are available from the corresponding author upon reasonable request.

\section{Conflicts of Interest}

The authors report no conflicts of interest.

\section{Authors' Contributions}

JJ, N-JP, S-NK, and MHY conceived and designed the study. JJ, N-JP, and S-YL performed the experiments. N-JP and B-G-J extracted data and performed data analyses. JJ, N-JP, $\mathrm{S}-\mathrm{NK}$, and $\mathrm{MHY}$ contributed to the literature search and proofreading of the manuscript. All authors validated it. Jonghwan Jegal and No-June Park contributed equally to this work.

\section{Acknowledgments}

This research was supported by the Bio \& Medical Technology Development Program of the National Research Foundation (NRF) funded by the Ministry of Science \& ICT (NRF-2019M3A9I3080263, NRF-2019M3A9I3080265, and NRF-2019M3A9I3080266).

\section{References}

[1] M. Peiser, T. Tralau, J. Heidler et al., "Allergic contact dermatitis: epidemiology, molecular mechanisms, in vitro methods and regulatory aspects," Cellular and Molecular Life Sciences, vol. 69, no. 5, pp. 763-781, 2012.

[2] G. Girolomoni, S. Sebastiani, C. Albanesi, and A. Cavani, "Tcell subpopulations in the development of atopic and contact allergy," Current Opinion in Immunology, vol. 13, no. 6, pp. 733-737, 2001.

[3] J. Correa da Rosa, D. Malajian, A. Shemer et al., "Patients with atopic dermatitis have attenuated and distinct contact hypersensitivity responses to common allergens in skin," Journal of Allergy and Clinical Immunology, vol. 135, no. 3, pp. 712720, 2015.

[4] H. Watanabe, M. Unger, B. Tuvel, B. Wang, and D. N. Sauder, "Review: contact hypersensitivity: the mechanism of immune responses and T cell balance," Journal of Interferon \& Cytokine Research, vol. 22, no. 4, pp. 407-412, 2002.

[5] S. Grabbe and T. Schwarz, "Immunoregulatory mechanisms involved in elicitation of allergic contact hypersensitivity," Immunology Today, vol. 19, no. 1, pp. 37-44, 1998.

[6] T. Honda, G. Egawa, S. Grabbe, and K. Kabashima, "Update of immune events in the murine contact hypersensitivity model: toward the understanding of allergic contact dermatitis," Journal of Investigative Dermatology, vol. 133, no. 2, pp. 303-315, 2013.
[7] P. Saint-Mezard, M. Krasteva, C. Chavagnac et al., "Afferent and efferent phases of allergic contact dermatitis (ACD) can be induced after a single skin contact with haptens: evidence using a mouse model of primary ACD," Journal of Investigative Dermatology, vol. 120, no. 4, pp. 641-647, 2003.

[8] C. Moulon, J. Peguet-Navarro, P. Courtellemont, G. Redziniak, and D. Schmitt, "In vitro primary sensitization and restimulation of hapten-specific $\mathrm{T}$ cells by fresh and cultured human epidermal Langerhans' cells," Immunology, vol. 80, no. 3, pp. 373-379, 1993.

[9] H. U. Weltzien, C. Moulon, S. Martin, E. Padovan, U. Hartmann, and J. Kohler, "T cell immune responses to haptens. Structural models for allergic and autoimmune reactions," Toxicology, vol. 107, no. 2, pp. 141-151, 1996.

[10] A. D. Christensen and C. Haase, "Immunological mechanisms of contact hypersensitivity in mice," Apmis, vol. 120, no. 1, pp. 1-27, 2012.

[11] R. Tsao, "Chemistry and biochemistry of dietary polyphenols," Nutrients, vol. 2, no. 12, pp. 1231-1246, 2010.

[12] M. L. Falcone Ferreyra, S. P. Rius, and P. Casati, "Flavonoids: biosynthesis, biological functions, and biotechnological applications," Frontiers in Plant Science, vol. 3, pp. 1-15, 2012.

[13] G. Di Carlo, N. Mascolo, A. A. Izzo, and F. Capasso, "Flavonoids: old and new aspects of a class of natural therapeutic drugs," Life Sciences, vol. 65, no. 4, pp. 337-353, 1999.

[14] C. Manach and J. L. Donovan, "Invited review," Free Radical Research, vol. 38, no. 8, pp. 771-785, 2004.

[15] Y. Kumazawa, K. Kawaguchi, and H. Takimoto, "Immunomodulating effects of flavonoids on acute and chronic inflammatory responses caused by tumor necrosis factor $\alpha$." Current Pharmaceutical Design, vol. 12, no. 32, pp. 4271-4279, 2006.

[16] L. Marzocchella, M. Fantini, M. Benvenuto et al., "Dietary flavonoids: molecular mechanisms of action as anti-inflammatory agents," Recent Patents on Inflammation \& Allergy Drug Discovery, vol. 5, no. 3, pp. 200-220, 2011.

[17] M. Kimata, N. Inagaki, and H. Nagai, "Effects of luteolin and other flavonoids on IgE-mediated allergic reactions," Planta Medica, vol. 66, no. 1, pp. 25-29, 2000.

[18] M. Kawai, T. Hirano, S. Higa et al., "Flavonoids and related compounds as anti-allergic substances," Allergology International, vol. 56, no. 2, pp. 113-123, 2007.

[19] V. Karuppagounder, S. Arumugam, R. A. Thandavarayan, R. Sreedhar, V. V. Giridharan, and K. Watanabe, "Molecular targets of quercetin with anti-inflammatory properties in atopic dermatitis," Drug Discovery Today, vol. 21, no. 4, pp. 632-639, 2016.

[20] V. Karuppagounder, S. Arumugam, R. A. Thandavarayan et al., "Modulation of HMGB1 translocation and RAGE/NF $\kappa$ B cascade by quercetin treatment mitigates atopic dermatitis in NC/Nga transgenic mice," Experimental Dermatology, vol. 24, no. 6, pp. 418-423, 2015.

[21] J. K. Choi, Y. H. Jang, S. Lee et al., "Chrysin attenuates atopic dermatitis by suppressing inflammation of keratinocytes," Food and Chemical Toxicology, vol. 110, pp. 142-150, 2017.

[22] S. Suroowan and F. M. Mahomoodally, "Wikstroemia indica," in Underexplored Medicinal Plants from Sub-Saharan Africa, pp. 295-301, Academic Press, Cambridge, MA, USA, 2020.

[23] Y. K. Rao, S.-H. Fang, and Y.-M. Tzeng, "Inhibitory effects of the flavonoids isolated from waltheria indica on the production of NO, TNF- $\alpha$ and IL-12 in activated macrophages," Biological \& Pharmaceutical Bulletin, vol. 28, no. 5, pp. 912915, 2005. 
[24] M. Dueñas, S. González-Manzano, A. González-Paramás, and C. Santos-Buelga, "Antioxidant evaluation of O-methylated metabolites of catechin, epicatechin and quercetin," Journal of Pharmaceutical and Biomedical Analysis, vol. 51, no. 2, pp. 443-449, 2010.

[25] C.-L. Lu, L. Zhu, J.-H. Piao, and J.-G. Jiang, "Chemical compositions extracted from Wikstroemia indica and their multiple activities," Pharmaceutical Biology, vol. 50, no. 2, pp. 225-231, 2012.

[26] S. Y. Lee, N. J. Park, J. Jegal et al., "Suppression of DNCBinduced atopic skin lesions in mice by Wikstroemia indica extract," Nutrients, vol. 12, no. 1, p. 173, 2020.

[27] A. Baroni, E. Buommino, V. De Gregorio, E. Ruocco, V. Ruocco, and R. Wolf, "Structure and function of the epidermis related to barrier properties," Clinics in Dermatology, vol. 30, no. 3, pp. 257-262, 2012.

[28] T. J. Hudson, "Skin barrier function and allergic risk," Nature Genetics, vol. 38, no. 4, pp. 399-400, 2006.

[29] M. J. Cork, D. A. Robinson, Y. Vasilopoulos et al., "New perspectives on epidermal barrier dysfunction in atopic dermatitis: gene-environment interactions," Journal of Allergy and Clinical Immunology, vol. 118, no. 1, pp. 3-21, 2006.

[30] M. Boguniewicz and D. Y. M. Leung, "Atopic dermatitis: a disease of altered skin barrier and immune dysregulation," Immunological Reviews, vol. 242, no. 1, pp. 233-246, 2011.

[31] L. S. Fonacier, S. C. Dreskin, and D. Y. M. Leung, "Allergic skin diseases," Journal of Allergy and Clinical Immunology, vol. 125, no. 2, pp. S138-S149, 2010.

[32] D. Y. M. Leung, "New insights into atopic dermatitis: role of skin barrier and immune dysregulation," Allergology International, vol. 62, no. 2, pp. 151-161, 2013.

[33] R. Darlenski, S. Sassning, N. Tsankov, and J. W. Fluhr, "Noninvasive in vivo methods for investigation of the skin barrier physical properties," European Journal of Pharmaceutics and Biopharmaceutics, vol. 72, no. 2, pp. 295-303, 2009.

[34] R. Marsella, T. Olivry, and D.-N. Carlotti, "Current evidence of skin barrier dysfunction in human and canine atopic dermatitis," Veterinary Dermatology, vol. 22, no. 3, pp. 239248, 2011.

[35] C. Traidl, F. Jugert, H. Merk, T. Krieg, and N. Hunzelmann, "Inhibition of allergic contact dermatitis to DNCB but not to oxazolone in interleukin-4-deficient mice," Journal of Investigative Dermatology, vol. 112, no. 4, pp. 476-482, 1999.

[36] Y. Hatano, Y. Adachi, P. M. Elias et al., "The Th2 cytokine, interleukin-4, abrogates the cohesion of normal stratum corneum in mice: implications for pathogenesis of atopic dermatitis," Experimental Dermatology, vol. 22, no. 1, pp. 30-35, 2013.

[37] E. Passante, C. Ehrhardt, H. Sheridan, and N. Frankish, "RBL$2 \mathrm{H} 3$ cells are an imprecise model for mast cell mediator release," Inflammation Research, vol. 58, no. 9, pp. 611-618, 2009.

[38] E. Passante and N. Frankish, "The RBL-2H3 cell line: its provenance and suitability as a model for the mast cell," Inflammation Research, vol. 58, no. 11, pp. 737-745, 2009.

[39] J. Punnonen, G. Aversa, B. G. Cocks et al., "Interleukin 13 induces interleukin 4-independent IgG4 and IgE synthesis and CD23 expression by human B cells," Proceedings of the National Academy of Sciences, vol. 90, no. 8, pp. 3730-3734, 1993. 